\title{
Effective enforcement of occupational health and safety regulation: an economic approach
}

Citation for published version (APA):

Faure, M. G., \& Tilindyte, L. (2010). Effective enforcement of occupational health and safety regulation: an economic approach. European Labour Law Journal, 1(3), 346-367. https://doi.org/10.1177/201395251000100304

Document status and date:

Published: 01/01/2010

DOI:

10.1177/201395251000100304

Document Version:

Publisher's PDF, also known as Version of record

Document license:

Taverne

Please check the document version of this publication:

- A submitted manuscript is the version of the article upon submission and before peer-review. There can be important differences between the submitted version and the official published version of record.

People interested in the research are advised to contact the author for the final version of the publication, or visit the DOI to the publisher's website.

- The final author version and the galley proof are versions of the publication after peer review.

- The final published version features the final layout of the paper including the volume, issue and page numbers.

Link to publication

\footnotetext{
General rights rights.

- You may freely distribute the URL identifying the publication in the public portal. please follow below link for the End User Agreement:

www.umlib.nl/taverne-license

Take down policy

If you believe that this document breaches copyright please contact us at:

repository@maastrichtuniversity.nl

providing details and we will investigate your claim.
}

Copyright and moral rights for the publications made accessible in the public portal are retained by the authors and/or other copyright owners and it is a condition of accessing publications that users recognise and abide by the legal requirements associated with these

- Users may download and print one copy of any publication from the public portal for the purpose of private study or research.

- You may not further distribute the material or use it for any profit-making activity or commercial gain

If the publication is distributed under the terms of Article $25 \mathrm{fa}$ of the Dutch Copyright Act, indicated by the "Taverne" license above, 


\title{
EFFECTIVE ENFORCEMENT OF OCCUPATIONAL HEALTH AND SAFETY REGULATION: AN ECONOMIC APPROACH
}

\author{
Michael G. FAure ${ }^{\star}$ \\ LAura Tilindyte ${ }^{* *}$
}

\begin{abstract}
The expanding body of regulation to address occupational health and safety risks does not inevitably lead to improved health and safety outcomes if regulation is not enforced properly. This paper uses an economic approach to establish what are cost-effective techniques (inspection, education, sanctions) to enforce occupational health and safety regulation. The paper argues that proactive inspections play a crucial role and should be given priority in enforcement work. At the same time, it identifies conditions under which proactive inspections may prove cost-effective as well. The paper addresses the issue of post-detection discretion and holds that there are sound economic reasons for granting labour inspectorates such discretion. It analyses what role criminal law should play in enforcement of occupational health and safety regulation, particularly when compared to the less stringent systems of administrative penalties. It is argued that for most cases administrative penalties are sufficient to ensure deterrence and compliance whereas criminal law may well play an important residual role under certain circumstances, which the paper specifies. The paper briefly considers the role of complementary sanctions such as naming and shaming and addresses the role that third parties could play in enforcement of occupational health and safety regulation.
\end{abstract}

Keywords: administrative penalties; criminal law; law and economics; occupational health and safety regulation; private enforcement

Michael G. Faure is Professor of Comparative and International Environmental Law at Maastricht University and Academic Director of the Maastricht Institute for Transnational Legal Research (METRO).

** Laura Tilindyte is Researcher at the Maastricht Institute for Transnational Legal Research (METRO). 


\section{INTRODUCTION}

Recent decades have seen a considerable increase in regulation to address occupational health and safety (OHS) risks. Whereas the need for safety regulation as such is hardly disputed, the enforcement aspect remains a crucial and contentious issue. Scholars disagree concerning the desirable degree of agency discretion, the role of punishment and, particularly, the role of criminal prosecutions in OHS enforcement. ${ }^{1}$ Moreover, faced with shrinking resources available in enforcement work, labour inspectorates are increasingly forced to deploy them as effectively as possible. This paper uses an economic approach to establish which enforcement techniques are cost-effective in ensuring compliance with OHS regulation. In this regard, cost-effective measures are defined as measures which achieve a high level of compliance at the lowest cost.

From an economic point of view, enforcement of OHS regulation by labour inspectorates creates incentives for employers to comply. Among other things, this can be done through increasing the probability of detection by means of frequent inspections and/or through sanctioning via administrative or criminallaw. With regard to labour inspection, a broad distinction can be drawn between reactive and proactive techniques. Proactive inspections generally aim at plants in which contraventions are most likely but are carried out even if no proof of a violation exists. Clearly, it requires more inspections and demands considerable resources in general. Reactive inspections are conducted in response to complaints about violations or accidents. They are much less costly and may still prove effective under certain conditions. This paper aims at formulating predictions of what these conditions might be.

After noncompliance is detected in the course of labour inspection, the next crucial question arises in how far inspectors should be given autonomy to adapt their enforcement responses to the particularities of the individual case. Therefore, next to the monitoring aspect, the paper addresses the issue of regulatory discretion in dealing with OHS violations and briefly discusses the deterrent and the cooperative style of enforcement. It then analyses optimal sanctioning methods, in particular the role of criminal law in OHS enforcement as opposed to the less stringent systems of administrative penalties. The final goal of this paper is to provide a theoretical model based on economic analysis indicating what enforcement techniques are costeffective in inducing compliance with OHS regulation. To this end, we can rely on general models of regulatory enforcement as well as on their applications in the fields

See for example the discussion between Pearce/Tombs and Hawkins: Pearce, F., and Tombs, S. (1990). Ideology, Hegemony, and Empiricism. Compliance Theories of Regulation. The British Journal of Criminology. 30(4): 423-443, Hawkins, K. (1990). Compliance Strategy, Prosecution Policy, and Aunt Sally. A Comment on Pearce and Tombs. British Journal of Criminology. 30(4): 444-466, Hawkins, K. (1991). Enforcing Regulation. More of the Same from Pearce and Tombs. Brittish Journal of Criminology. 31(4): 427-430. See also the more recent publication of Tombs and Whyte in which the authors vehemently argue in favour of more criminalisation of OHS offences: Tombs, S., and Whyte, D. (2007), Safety Crimes, Portland, Willan Publishing. 
of consumer and environmental legislation. To some extend, we make use of this literature and compare it with the particular situation of OHS or rely on the existing economic models of OHS enforcement. ${ }^{2}$

The paper is structured as follows: first, we briefly sketch the basic ideas behind the economic model of enforcement, starting from the idea that an employer should be given optimal incentives to comply (2). Next, we discuss traditional arguments put forward in law and economics literature concerning private versus public enforcement and argue that there are strong arguments in favour of public enforcement of OHS regulation (3). Then, we address the different monitoring models which exist to detect OHS violations (4). After doing so, we pose the question whether it is advisable to grant agencies post-detection discretion allowing them to adapt their enforcement responses to the situation of a particular case (5). In the next section we demonstrate that public enforcement should not necessarily imply the use of the criminal law since administrative law can provide cost-effective incentives for compliance as well (6). Next, the question is addressed what are the optimal sanctions for violations (7). After having considered the role of public agencies, the question also arises to what extent third parties, more particularly employees and trade unions, can play a useful role in the enforcement of OHS regulation (8). Finally, concluding remarks are formulated (9).

\section{OPTIMAL ENFORCEMENT OF OHS REGULATION: AN ECONOMIC APPROACH}

The economic approach to law enforcement goes back to the seminal paper by Becker who basically has argued that people do not act illegally unless the expected benefits of doing so exceed the expected costs of illegal behaviour. The expected costs are determined by multiplying the probability of detection and sanction with the severity of the sanction. ${ }^{3}$ Based on this deterrence hypothesis, ${ }^{4}$ the rich literature on economics of crime and law enforcement suggests that potential offenders respond to the incentives created by the criminal justice system: crime rates hence inter alia

2 See for example Viscusi, W.K. (1986). The Structure and Enforcement of Job Safety Regulation. Law and Contemporary Problems. 49(4): 127-150, Scholz, J.T., and Gray, W.B. (1990). OSHA Enforcement and Workplace Injuries: A Behavioral Approach to Risk Assessment. Journal of Risk and Uncertainty. 3(3): 283-305, Oi, W.Y. (1974). On the Economics of Industrial Safety. Law and Contemporary Problems. 38(4): 669-699.

3 Becker, G.S. (1968). Crime and Punishment: An Economic Approach. Journal of Political Economy. 76(2): 169-217.

4 The economic approach does not distinguish between specific deterrence (aimed at deterring one specific individual from committing (another) violation by applying a sanction to him/her) and general deterrence (arguing that potential offenders will generally be deterred from violating the law through the sanctions that could follow). Implicitly the economic approach is, however, mostly geared towards general deterrence. 
depend on the risks and benefits of crime. ${ }^{5}$ The starting point of this suggestion is that criminals are rational utility maximizers who base their decisions to commit or not to commit a crime on an expected utility calculation. They weigh the costs and benefits of compliance and non-compliance with the law and do not act illegally unless the expected benefits exceed the expected costs. Clearly, this assumption has been highly criticized in literature and is not plausible in relation to many criminal activities. ${ }^{6}$ Yet, within the context of occupational safety, it is much more useful since potential violators are corporate actors who very well - at least partly - base their decisions on a cost-benefit analysis. ${ }^{7}$ Accordingly, employers will comply with safety regulation as long as the costs of safety improvements are lower than the expected costs of non-compliance. The greater the enforcement activity (inspection, penalties etc.), the stronger the incentives to comply.

The costs of non-compliant behaviour may be raised through increasing the probability of detection, the sanction or by variations of both. Raising the probability of being caught requires more and better inspection and is costly. Increasing the expected maximum punishment, to the contrary, requires less effort from the government and inflicts less costs on society. ${ }^{8}$ Therefore, an argument was made in economic literature that the maximization of social welfare requires applying maximal fine since fines are costless to apply whereas detection is costly. ${ }^{9}$ The use of fines as an effective deterrent, however, is not unproblematic. Fines only work in case of full solvency of the employer who has sufficient assets to pay them. In case of insolvency, applying fines may lead to under-deterrence. ${ }^{10}$ To overcome this problem, Shavell for example suggested that non-monetary sanctions will have to be applied. ${ }^{11}$ Fines for OHS offences, moreover, have been criticized in literature because they do not induce structural change within firms to prevent violations in the future. ${ }^{12}$ Finally, empirical evidence has shown that it may be much more effective to raise the probability of detection instead of

5 Garoupa, N. (1997). The Theory of Optimal Law Enforcement. Journal of Economic Surveys. 11(3): 267-295.

6 Faure, M.G., and Visser, M. (2004). Law and Economics of Environmental Crime. In H. Sjögren, and G. Skogh (Eds.), New Perspectives on Economic Crime. 57-75: Edward Elgar Publishing.

7 See for example Braithwaite, J., and Geis, G. (1982). On Theory and Action for Corporate Crime Control. Crime and Delinquency. 28(2): 292-314.

8 Posner, R.A. (1979). Optimal Sentences for White Collar Criminals. American Criminal Law Review. 17: 400-418.

$9 \quad$ Kobayashi, B.H., and John R. Lott, J. (1992). Low Probability-High-Penalty Enforcement Strategies and the Efficient Operation of the Plea-Bargaining System. International Review of Law and Economics. 12(1): 69-77.

10 Coffee, J.C. (1981). "No Sould to Damn: No Body to Kick": An Unscandalized Inquiry into the Problem of Corporate Punishment. Michigan law Review. 79(3): 386-459.

11 Shavell, S. (1985). Criminal Law and the Optimal Use of Non-Monetary Sanctions. Columbia Law Review. 85: 1232-1262.

12 For these as well as other shortcomings of fines see Gunningham, N., and Johnstone, R. (1999). Regulating Workplace Safety: Systems and Sanctions. Oxford: Oxford University Press, pp. 256259. 
combining a low probability of detection with a high sanction. ${ }^{13}$ Particularly given the risk of insolvency, raising the probability of detection may give better results than adopting a policy of high sanctions.

Raising the probability that OHS violations are detected requires more and better labour inspection and is costly. The resources of labour inspectorates are, however, severely limited in practice. ${ }^{14}$ Higher costs of enforcement may be justified if it leads to stronger deterrence or educational effects. Preventing all breaches is, however, neither possible nor desirable, since the costs of achieving it would inevitably outweigh the benefits. The desired outcome thus becomes a high level of compliance at least cost, an approach referred to as cost-effectiveness. ${ }^{15}$ Before coming to the question what are cost-effective techniques in OHS enforcement, the issue is addressed why there should be public OHS enforcement via state agencies in the first place.

\section{PRIVATE VERSUS PUBLIC ENFORCEMENT}

In theory, public regulation such as OHS could also be enforced privately. In such a case one would refer to enforcement by interested parties such as employees and trade unions. The alternative to private enforcement is that public authorities intervene to monitor OHS compliance and sanction non-compliance. Law and economics literature has paid considerable attention to the possibilities of private law enforcement. ${ }^{16}$ It identified the so-called rational apathy problem, explaining why victims may have insufficient incentives privately to enforce laws. ${ }^{17}$ It follows the general problem identified by Shavell that there may be a divergence between the private and social motives to bring a lawsuit. ${ }^{18}$ Within the context of consumer protection legislation, Van den Bergh recently identified what are the conditions under which a consumer may file a private law suit in case of violation of consumer protection legislation. His arguments are that this strongly depends upon the nature of the offence (individual damage or widespread damage), possibilities to exclude free riding of third parties who may benefit from the suit, the interests at stake and the corresponding litigation

13 Ehrlich, I. (1973). Participation in Illegitimate Activities: A Theoretical and Empirical Investigation. Journal of Political Economy. 81(3): 521-565.

14 Gunningham, N., and Johnstone, R. (1999). Regulating Workplace Safety: Systems and Sanctions. Oxford: Oxford University Press.

15 Ogus, A., Faure, M., and Philipsen, N. (2006). Best Practices for Consumer Policy: Report on the Effectiveness of Enforcement Regimes. Paris: OECD, Committee on Consumer Policy, Levin, H.M. (1983). Cost-Effectiveness: a Primer. Beverly Hills: Sage.

16 Landes, W.M., and Posner, R.A. (1975). The Private Enforcement of Law. Journal of Legal Studies. 4(2): 1-46.

17 Schaefer, H.-B. (2000). The Bundling of Similar Interests on Litigation. The Incentives for Class Actions and legal Actions Taken by Associations. European Journal of Law and Economics. 9(3): 183-213.

18 Shavell, S. (1997). The Fundamental Divergence between the Private and the Social Motive to Use the Legal System. Journal of Legal Studies. 26: 575-612. 
costs. ${ }^{19}$ To this, one could add the 'classic' criteria advanced by Shavell indicating under which circumstances safety regulation is more efficient than liability rules. ${ }^{20}$ These criteria can equally be considered as criteria in favour of public rather than private enforcement. The first criterion is information: employees may often lack the necessary information concerning the content of applicable rules to enforce OHS regulation privately. The second criterion of Shavell is the insolvency risk, meaning that private enforcement only provides optimal incentives when employers are able to compensate the harm done. Third, due to limited liability of the employer, both the compensatory and the deterrent effect of tort law may be limited. In theory, 'piercing the corporate veil' or shareholder's liability advocated by some authors ${ }^{21}$ may remedy this problem. Yet, due to difficulties arising from this approach, public enforcement of OHS regulation may be a better way to ensure the necessary incentives. Finally, Shavell also indicates that private enforcement may fail when a tortfeasor (the employer in our example) is not facing the threat of a law suit. A number of factors might influence this: dispersal of harm, the latency problem or causal uncertainty. These factors seem to be more relevant in cases of occupational diseases, particularly the latency problem and causal uncertainty, ${ }^{22}$ but there may be other equally important obstacles for an employee to bring a lawsuit against his or her employer following an accident. First, it might be difficult to attribute harm to responsible parties, especially in big corporate structures. Second, lawsuits imply high legal costs in general and victims have to satisfy a high burden of proof. This might be particularly difficult when for example vague standards or general duties of the employer are violated. Also employees may fear to bring a lawsuit against their employers since this can easily lead to the loss of job or have other adverse consequences. Consequently, the probability of liability suits against employers may be relatively low.

The conclusion from the application of this economic literature to the case of enforcement of OHS regulation seems to be clear: employees may have too little incentives to bring suits against their employers for violating OHS legislation. Moreover, private enforcement by employees is necessarily harm based and will therefore only take place after an accident occurs. It is, however, very well possible that violations of OHS regulation take place without harm occurring. Since in those cases no individual victim suffers loss, private enforcement action will not follow.

19 Van den Bergh, R. (2007). Should Consumer Protection Law be Publicly Enforced? An Economic Perspective on a EC Regulation 2006/2004 and its Implementation in the Consumer Protection Laws of the Member States. In W.V. Boom, and M. Loos (Eds.), Collective Enforcement of Consumer Law. Securing Compliance in Europe Private Group Action and Public Authority Intervention. Groningen: Europa Law Publishing.

20 Shavell, S. (1984). Liability For Harm Versus Regulation of Safety. The Journal of Legal Studies. 13(2): 357-374.

21 Kraakman, R.H. (1984). Corporate Liability Strategies and the Costs of Legal Controls. Yale Law Journal. 93: 857-898.

22 Danzon, P.M. (1987). Compensation for Occupational Diseases: Evaluating the Options. The Journal of Risk and Insurance. 54: 263-282. 
These are hence all strong reasons in favour of public enforcement of OHS regulation by state authorities which inspect, warn, educate and, if necessary, punish. This brings us back to the question what monitoring techniques state authorities should employ to monitor OHS compliance.

\section{MONITORING MODELS}

The first question which needs to be answered in designing an optimal enforcement system is what type of approach labour inspectorates will follow with regard to monitoring of compliance. A broad distinction can be made between a proactive and a reactive monitoring system. Proactive monitoring implies that agencies inspect workplaces ex ante upon their own initiative, even if no evidence of a contravention exists. Inspections are preferably planned on the basis of a risk assessment model indicating where contraventions are most likely to occur, or on a random basis. Reactive monitoring refers to an agency's action which is triggered by a third party complaint following a violation or an accident. ${ }^{23}$ Within the OHS context, these complaints would naturally come from either employees, trade unions or other interested parties.

When choosing between proactive or reactive monitoring, all things being equal, it is not difficult to argue that proactive monitoring is costlier than reactive. Proactive monitoring requires generally more inspections as well as an informed targeting of workplaces on the basis of their compliance record. Reactive monitoring on the other hand takes place in a far more targeted way since inspection costs are only incurred in reaction to a complaint. In literature with respect to consumer protection regulation, criteria have been developed to indicate under what circumstances either proactive or reactive monitoring might be more warranted. The starting point is, as indicated, that proactive monitoring is costlier than reactive. Therefore, proactive monitoring should in principle only be chosen when reasons exist why reactive monitoring might be ineffective. ${ }^{24} \mathrm{~A}$ first indicator is whether there is already a strong culture of employee activism with e.g. trade unions and employees who actively monitor compliance with health and safety regulation and who take action against a defaulting employer. However, in the context of consumer law it was indicated that third parties (more particularly consumer associations) may either take insufficient action against violations or misuse enforcement powers for opportunistic reasons. ${ }^{25}$

23 The distinction between proactive and reactive system of law goes back to publications by Black, D.J. (1970). Production of Crime Rates. American Sociological Review. 35(4): 733-748, Black DJ (1971), 'The Social Organization of Arrest', Stanford Law Review, 23(6), pp. 1087-1111, Black DJ (1973), 'The Mobilization of Law', Journal of Legal Studies, 2, pp. 125-149.

24 Ogus, A., Faure, M., and Philipsen, N. (2006). Best Practices for Consumer Policy: Report on the Effectiveness of Enforcement Regimes. Paris: OECD, Committee on Consumer Policy.

25 Schaefer, H.-B. (2000). The Bundling of Similar Interests on Litigation. The Incentives for Class Actions and legal Actions Taken by Associations. European Journal of Law and Economics. 9(3): 
These and similar arguments were dealt with above when the choice between public versus private enforcement were discussed. Mainly the same reasons which inhibit employees from bringing lawsuits against their employers may equally prevent them from filing complaints about OHS violations at their workplace.

The second criterion advanced in literature is related to the type of regulation which has to be enforced as well as the information available to employees concerning the applicable law. If employees or trade unions are poorly informed about the contents of the rules or are unlikely to detect their violations, it is quite unlikely that they will report them. Moreover, this may depend on the type of standard involved: whereas it is easier for employees to report non-compliance with specific and clear-cut standards (such as the absence of prescribed protective equipment or machinery), it may be much more difficult to establish violations of unclear or complex rules.

An argument related to this is the information available to employers concerning the contents of the rules. ${ }^{26}$ If employers are poorly informed concerning the rules and means to comply with them, a proactive monitoring system may have the advantage of providing information to the employer and fulfilling an important educative role. ${ }^{27}$ In contrast, reactive inspections imply that something went wrong already. This leaves less scope for education and for inspectors' discretion in general and may incline the agency to a tougher enforcement response. ${ }^{28}$ Again, the extent to which employers need additional information on the applicable rules may well differ with the types of standards that are being enforced. Some standards tell an employer precisely what preventive measures to take and require little judgement on his part. These are often referred to as specification standards. Other standards contain general duties or can be broad process based standards, requiring certain steps to be taken in improving OHS. ${ }^{29}$ Assisting duty holders in providing information on the contents of the duties may well be more important in case of vague, unclear or complex standards.

Finally, it is of importance whether the contractual relationship between the employer and employee may inhibit employees from filing complaints. The fact that they are in a repeat player game situation with the employer and may fear sanctions may also reduce the effectiveness of reactive monitoring. Clearly, the possibilities of anonymous

\section{$183-213$.}

26 Faure, M., Ogus, A., and Philipsen, N. (2009). Curbing Consumer Financial Losses: The Economics of Regulatory Enforcement. Law and Policy. 31(2): 161-191.

27 Hutter, B.M. (1986). An Inspector Calls. The importance of proactive enforcement in the regulatory context. British Journal of Criminology. 26(2): 114-128.

28 Richardson, G., Ogus, A., and Burrows, P. (1982). Policing Pollution. A Study of Regulation and Enforcement. Oxford: Clarendon Press, p. 123, 176.

29 Bluff, E., and Gunningham, N. (2004). Principle, Process, Performance or What? New Approaches to OHS Standards Setting. In L. Bluff, N. Gunningham, and R. Johnstone (Eds.), OHS for a Changing World of Work. 12-42. Sydney: Federation Press. 
complaints mitigate this problem to some extent and generally agencies agree not to reveal that a complaint has been made at all. ${ }^{30}$

In addition, we can add another criterion which may more particularly play a role in case of enforcement of OHS regulation, namely the protected interest of the regulation. If regulation only aims at protecting financial interests (like is often the case with consumer laws), a reactive system does not necessarily result in high (irreparable) social damage if violations are not easily detected. If, however, not only financial interests, but also human health or life is at stake, it may be argued that the higher value of those protected interests is a strong argument in favour of proactive monitoring. In economic terms, society may be willing to invest higher costs of proactive (compared to reactive) monitoring given that the social damage resulting from violation might be higher as well.

The discussion of the proactive versus reactive inspection should not, however, be read in either-or terms. The fact that the inspectorate will often have to enforce various standards of a potentially different nature also implies that reactive and proactive monitoring will be combined in practice. Yet, the discussion above indicates that reactive inspections alone are not sufficient to ensure compliance and highlights the role of proactive work. After all, proactive inspections may not be as expensive as it might seem if an already existing agency network is available. If public agencies are already available to monitor and inspect, the marginal costs of proactive monitoring are likely to be smaller than when the agency for monitoring OHS compliance would have to be set up from scratch.

Suggestions have also been formulated in literature based on empirical studies on the effectiveness of varying monitoring techniques. With respect to consumer legislation, ${ }^{31}$ environmental law $^{32}$ as well as with respect to OHS regulation, it has been shown that the effectiveness of inspections can be increased by a targeting of the enforcement efforts on specific segments of the regulated community. ${ }^{33}$ This favours targeting of workplaces on the basis of risk assessment models which rely on objective

$30 \quad$ Hutter, B.M. (1986). An Inspector Calls. The importance of proactive enforcement in the regulatory context. British Journal of Criminology. 26(2): 114-128.

31 Van den Bergh, R. (2007). Should Consumer Protection Law be Publicly Enforced? An Economic Perspective on a EC Regulation 2006/2004 and its Implementation in the Consumer Protection Laws of the Member States. In W.V. Boom, and M. Loos (Eds.), Collective Enforcement of Consumer Law. Securing Compliance in Europe Private Group Action and Public Authority Intervention. Groningen: Europa Law Publishing.

32 Rousseau, S. (2007). Timing of environmental inspections: survival of the compliant. Journal of Regulatory Economics. 32(1): 17-36, Friesen, L. (2003). Targeting enforcement to improve compliance with environmental regulations. Journal of Environmental Economics and Management. 46(1): 7285.

33 Within the US context, see for example Haviland, A.M., Burns, R.M., Gray, W., Ruder, T., Mendeloff, J. (2008), The Impact of OSHA Inspections on Lost Time Injuries in Manufacturing. Pennsylvania Manufacturing 1998-2005, RAND Working Paper, retrieved August 2009 from www.rand.org/ pubs/working_papers/WR592/. 
criteria to indicate where more violations are likely instead of a random selection for inspection. ${ }^{34}$

Applying these criteria to the case of OHS regulation it is not difficult to argue that there are strong arguments in favour of a proactive monitoring. First, the reactive approach may be cost-effective only in legal systems where there is a strong culture of employee activism and one can thus expect reporting of complaints. Especially in countries where trade unions are weak that may be a problem. Related to this first argument is that the marginal costs of proactive monitoring in the case of OHS regulation is probably notveryhigh since in many cases a network oflabour inspectorates already exists. Second, some violations of OHS regulation may be quite difficult for employees or trade unions to detect. Easily visible violations e.g. concerning safety at a construction site may be visible, but for example violations of rules concerning the use of filters to prevent employees from inhaling certain dangerous fumes are much more complex. In this respect, one can generally make a rough distinction between rules aiming at the prevention of industrial accidents on the one hand versus rules aiming at the prevention of occupational diseases on the other. It is likely that employees can more easily detect violations of the first than of the second set of rules. Third, also in case of OHS regulation the argument can be made that future compliance can be enhanced by frequent inspections which can have an educating effect on employers on what is required by law and how to comply in a cost-effective manner. Especially in those cases where violations take place out of ignorance, which is particularly the case with small and medium-sized enterprises, proactive monitoring may play this educative role. This is particularly true in case of imprecise and vague standards. Also the criteria we added clearly seem to favour proactive monitoring: given that with OHS regulation (of course depending upon the types of standards that are enforced) not merely financial interests but human health is at stake as well, this may warrant additional investments required by proactive monitoring. Finally, even if employees are able to detect violations (which, given the complicated nature is not always easy), they may have reasons based on the relationship with the employer (fear of sanctions, missing a promotion etc.) not to report a violation. Given these criteria, there seem to be strong arguments that proactive inspections by public authorities are cost-effective and should be given priority in enforcement work. This preference for pro-active monitoring is especially strong when precise specification standards are at stake which aim at the prevention of serious risk. However, pro-active monitoring can always be combined with re-active (e.g. answering to complaints).

A disadvantage of such a proactive monitoring system based on the number of reported accidents is that this may create incentives to underreport accidents, as a study of Ruser and Smith has shown, Ruser, J.W., and Smith, R.S. (1988). The Effect of OSHA Records-Check Inspections on Reported Occupational Injuries in Manufacturing Establishments. Journal of Risk and Uncertainty. 1(4): 415-435. 


\section{POST-DETECTION DISCRETION}

The next question which arises is whether state agencies should be granted broad discretionary powers in enforcing regulation. In reality of OHS regulation one can notice that in many legal systems this discretion exists: public servants are not forced to impose a sanction or to inform the public prosecutor for every violation (unless the consequences would be very serious). Instead, they can resort to a broad array of instruments after a detection of a violation, which can be both formal and informal, legal (sanctions, legal proceedings) and extra-legal (education, advise, persuasion, negotiation). ${ }^{35}$ In cases of minor violations, officials often use discretionary powers by e.g. issuing a formal or informal warning or requiring from the violator compliance within a certain period of time without immediately resorting to prosecution.

The question of how far one allows agency discretion, is strongly linked to the enforcement style which is followed to induce compliance. It is an issue which has received a lot of attention in general economic literature with respect to enforcement styles and also in literature dealing with OHS regulation. ${ }^{36}$ Roughly two enforcement styles are distinguished (although the distinction is not as strict as one may think at first blush): 'deterrence' or 'compliance'. ${ }^{37}$ The economic approach is generally qualified as the deterrence style based on the idea that authorities should be tough with perpetrators and prosecute frequently, preferably resulting in severe sanctions. A deterrence model therefore, at first glance, does not seem to allow much scope for agency discretion. ${ }^{38}$ A cooperation enforcement style relies more heavily on negotiations between the regulated and the agency whereby the agency, through persuasion and advice, tries to bring the violator to compliance. Within this cooperation model punishment is not the appropriate instrument, but rather a method of last resort if other instruments (persuasion and information) have failed. ${ }^{39}$

At first blush, the cooperation model does not fit into the economic approach to enforcement. The classic Becker model assumes that the frequent imposition of severe sanctions in combination with a high detection rate will provide sufficient incentives for compliance. Another problem with the cooperation strategy is that when cooperation fails and the administrative agency has to change its position to a deterrent style, the cooperation and strong links between the employer and the agency may have made it difficult or even impossible to change to a punitive approach when

35 Hutter, B. (1997). Compliance: Regulation and Environment. Oxford: Oxford University Press.

36 Johnstone, R. (2004). Rethinking OHS Enforcement. In L. Bluff, N. Gunningham, and R. Johnstone (Eds.), OHS Regulation for a Changing World of Work. 146-178. Sydney: Federation Press.

37 As they were labeled by Reiss, A.J., Jr. (1984). Selecting Strategies of Social Control over Organizational Life. In K. Hawkins, and J.M. Thomas (Eds.), Enforcing Regulation: Kluwer-Nijhoff Publishing.

38 Nevertheless, also in the deterrence approach it is not supposed that every detected violation should be prosecuted for the simple reason that this may cost too much.

39 Hawkins, K., and Thomas, J.M. (1984). The Enforcement Process in Regulatory Bureaucracies. In K. Hawkins, and J.M. Thomas (Eds.), Enforcing Regulation: Kluwer-Nijhoff Publishing. 
necessary. Ayres and Braithwaite for example cautioned that the conditions which enhance the development of cooperation are at the same time also conditions which foster corruption and capture. ${ }^{40}$ The cooperation strategy has therefore the inherent risk that powerful companies will de facto control and 'capture' the agency. ${ }^{41}$

Notwithstanding these limits of the cooperation model, many have also pointed at the limits of the deterrence approach. It has been argued that a strict deterrence approach ignores the fact that compliance may be practically impossible or excessively difficult. This hence may lead to a refusal to comply because the deterrence approach is perceived as unreasonable. ${ }^{42}$ Moreover, enforcement agents may be unwilling to act as 'policeman' in an adversarial relationship with the regulated. ${ }^{43}$ The cooperative strategy even receives support from economists. It would be too simplistic to reject the cooperation style entirely because of the risk of capturing. Whereas the risk of abuse of discretionary powers in terms of corruption and capture cannot be ruled out completely, ${ }^{44}$ Hawkins for example has argued that the risk of such abuse should not be exaggerated. ${ }^{45}$ An advantage of the cooperation model is that through persuasion, education and information companies can be lead towards compliance. Fenn and Veljanovski, moreover, have argued that flexible enforcement cures the problem of over-inclusiveness of many legal rules and mitigate the "harshness" of many OHS standards. ${ }^{46}$ Another reason to follow the cooperation model can be related to the high costs for the enforcing agency to bring a case to court. ${ }^{47}$ Those high costs may also explain why in some cases there is a seemingly high tolerance of the enforcing agency to non-compliance; this can be a strategic response by the agency to a difficult enforcement environment. ${ }^{48}$ This may hence provide a rationalization of 'regulatory dealing' between the agency and the employer. Especially in cases where

$40 \quad$ Ayres, I., and Braithwaite, J. (1992). Responsive Regulation. Transcending the Deregulation Debate. New York: Oxford University Press.

41 Garoupa, N., and Klerman, D. (2004). Corruption and the optimal use of nonmonetary sanctions. International Review of Law and Economics. 24(2): 219-225.

42 Hawkins, K. (1984). Environment and Enforcement. Regulation and the Social Definition of Pollution. Oxford, Bardach, E., and Kagan, R. (1982). Going by the Book: The Problem of Regulatory Unreasonableness. Philadelphia: Temple University Press.

43 Aalders, M., and Wilthagen, T. (1997). Moving Beyond Command-and-Control: Reflexivity in the Regulation of Occupational Safety and Health and the Environment. Law \& Policy. 19(4): 415-443.

44 Kagan, R.A., and Scholz, J.T. (1984). The "Criminology of the Corporation" and Regulatory Enforcement Strategies. In K. Hawkins, and J.M. Thomas (Eds.), Enforcing Regulation. 67-95. Boston: Kluwer-Nijhoff.

45 Hawkins, K. (1984). Environment and Enforcement. Regulation and the Social Definition of Pollution. Oxford.

46 Fenn, P., and Veljanovski, C.G. (1988). A Positive Economic Theory of Regulatory Enforcement. The Economic Journal. 98(393): 1055-1070.

47 Rowan-Robinson, J., Watchman, P., and Barker, C. (1990). Crime and Regulation. A Study of the Enforcement of Regulatory Codes. Edinburgh: T\&T Clark.

48 Heyes, A., and Rickman, N. (1999). Regulatory Dealing - Revisiting the Harrington Paradox. Journal of Public Economics. 72: 361-378. 
administrative authorities are well informed and small and medium-sized enterprises are not, a cooperative strategy could lead to the situation whereby the agency assists the enterprise towards compliance with regulation.

In short, there is no such strict distinction between the deterrence and the cooperation enforcement styles as it might first seem. Both are ideal types which hardly exist in practice. Moreover, the desirable strategy in the individual case depends upon the OHS standards that are being enforced. For example, vague and imprecise standards such as general duties or performance standards leave more room for interpretation and hence considerable discretion to inspectors. In contrast, specification standards, informing the duty holder precisely what preventive measures to take require little judgement on the employer's part and possibly necessitate less assistance by the agency. ${ }^{49}$ They, therefore, leave less scope for regulatory discretion or may even incline inspectors towards a more punitive approach. Braithwaite therefore proposes to combine the enforcement styles: to start with informal and less intrusive enforcement options (persuasion, warnings) and to move to more punitive options (fines or criminal prosecution) when cooperation has failed. ${ }^{50}$

Applying these insights to the case of post-detection discretion after establishment of a violation of OHS regulation one can argue that there are, except in the case when there are justified fears that officials might abuse discretion, strong reasons in favour of granting agencies broad discretionary powers. It can allow a cost-effective differentiation by agencies focussing enforcement efforts on those employers who (e.g. as repeat offenders) continue to violate the regulation whereas scarce resources should not be wasted on employers who can be induced towards compliance after a warning. Moreover, especially in those cases where violations take place because of ignorance rather than wilful conduct to disobey the law, post-detection discretion can lead to a cooperative strategy whereby the health and safety inspectorate can induce the uninformed employer towards compliance. In contrast, where violations stem from wilful conduct or occur repeatedly, agencies may resort to more severe measures. Sanctions, therefore, will remain an important and inevitable element of a credible enforcement strategy. This leads us to the question what type of sanctioning mechanisms are cost-effective in OHS enforcement.

\section{ADMINISTRATIVE OR CRIMINAL LAW?}

In chapter 3, we presented the traditional economic arguments to explain why OHS violations cannot merely be remedied via private law and why public enforcement is

49 Bluff, E., and Gunningham, N. (2004). Principle, Process, Performance or What? New Approaches to OHS Standards Setting. In L. Bluff, N. Gunningham, and R. Johnstone (Eds.), OHS for a Changing World of Work. 12-42. Sydney: Federation Press. 
needed. The main reason is the low probability that employees or other third parties will detect a violation and file a private lawsuit. However, this does not necessarily explain why one should resort to criminal law. In theory, the low probability of detection may well be compensated by imposing a high fine on the employer. Traditionally, fines have been considered the preferred sanction in economic theory for the simple reason that the costs of their imposition are low and fines generate money for the public budget. ${ }^{51}$ Monetary sanctions in principle can be both criminal and administrative in nature. All things being equal, the administrative procedure has the major advantage that it is far less costly than the criminal procedure. Administrative fines can, within what is sometimes referred to as 'administrative penal law', ${ }^{2}$ be imposed by administrative authorities without engaging in lengthy court proceedings and after satisfying only a relatively low threshold of proof. In contrast, criminal law requires the state authority to prove beyond reasonable doubt that the offence has been committed. It can therefore be argued that if optimal deterrence can be achieved through fines, it seems desirable to use the less costly administrative law instead of the relatively more costly criminal procedure. However, there are two important reasons why not all efficient penalties necessary to deter violations of OHS regulation can be imposed through administrative law and why criminal law therefore remains necessary. The first reason is that since the probability of detection of OHS violations is in practice very low, ${ }^{53}$ the optimal sanction to deter violations may become very high. Consequently, the likelihood that this optimal fine might outweigh the individual wealth of an offender is relatively high. Employers are often organised as corporate entities that benefit from limited liability. ${ }^{54}$ Hence, in the criminal law context, there is always the risk that the optimal fine (to compensate for a low detection rate) will be much higher than the assets of the firm which means that non-monetary sanctions such as imprisonment might become necessary. ${ }^{55}$ Firms may, moreover, avoid paying fines by altering their corporate structures or identities. ${ }^{56}$ The benefits of non-compliance with OHS regulation may be huge for firms, since safety devices and other safety improvements require considerable investments and do not always lead to corresponding benefits for firms in the short term. The major advantage of the fine (lower administrative costs)

51 Posner, R.A. (1979). Optimal Sentences for White Collar Criminals. American Criminal Law Review. 17: 400-418.

52 This expression 'administrative penal law' may be confusing to some who consider 'penal' synonymous with 'criminal'. In the literature this notion is used to refer to a system whereby administrative authorities impose penalties.

53 See for example Gunningham, N., and Johnstone, R. (1999). Regulating Workplace Safety: Systems and Sanctions. Oxford: Oxford University Press, p. 105 and studies there cited.

54 Hansmann, H., and Kraakman, R. (1991). Toward Unlimited Shareholder Liability for Corporate Torts. Yale Law Journal. 100(7): 1879-1934.

55 Posner, R.A. (1985). An Economic Theory of the Criminal Law. Columbia Law Review. 85(6): 11931231.

56 Gunningham, N., and Johnstone, R. (1999). Regulating Workplace Safety: Systems and Sanctions. Oxford: Oxford University Press. 
therefore only speaks in favour of this type of sanction when the risk of insolvency can be controlled. It should also be recalled that, given a lower procedural threshold, the probability of an administrative fine being imposed is much higher. In contrast, agencies are known to be extremely reluctant to refer a case to the court and to seek criminal prosecution. ${ }^{57}$ As a result, the administrative fine should not necessarily be nearly as large as the criminal fine since the probability of the administrative fine to be imposed is higher. This in turn mitigates the insolvency problem.

There is, in addition, a second clear-cut reason why criminal law may be warranted from the moment that non-monetary sanctions need to be imposed. This is related to the fact that society does not want to impose very stringent sanctions, such as imprisonment (but also high fines) through an administrative proceeding. The reason is that the costs of the administrative proceedings are generally lower than the costs of the criminal proceedings, but the accuracy of the latter is much higher. This aspect is also important because a task of criminal law is not only to apply optimal sanctions to the guilty, but also to avoid punishing the innocent. ${ }^{58}$ In economic theory, this goal is referred to as reduction of error costs. ${ }^{59}$ The error costs are obviously a lot higher when very serious sanctions such as imprisonment are imposed and not monetary sanctions only. It is therefore understandable that the less costly administrative proceedings are chosen in all cases where the consequences (and thus the error cost) will not be too high in the event of a wrongful conviction. Arguably also a goal of the administrative procedure is to avoid punishing the innocent as well (and thus reducing error costs), although they operate at a lower standard. That explains why administrative law (and the corresponding administrative procedure) will be reserved for cases where relatively low penalties can suffice to provide deterrence.

The policy lesson from this economic literature is therefore straightforward: in cases where optimal deterrence of employers can be achieved through relatively modest sanctions such as non-crushing administrative penalties or other administrative sanctions, the use of the less costly administrative (penal) law may be warranted. However, in cases where the probability of detection is relatively low, social harm and the potential gain to the polluter high and thus a more severe sanction is needed, it may be warranted to use the more costly criminal procedure in order to reduce error costs. This is certainly the case when the optimal fine would reach the insolvency limit and non-monetary sanctions are thus needed for deterrence, but equally where for the same reason very high administrative fines would have to be imposed. For example when a violation of OHS regulation would have led to substantial harm to employees (for example in case of industrial accidents or occupational diseases) an administrative fine may not suffice to deter and the criminal law may be needed. It has also been

\footnotetext{
57 Hawkins, K. (1984). Environment and Enforcement. Regulation and the Social Definition of Pollution. Oxford.

58 Hart, H.M. (1958). The Aims of the Criminal Law. Law and Contemporary Problems. 23: 401-441.

59 Posner, R.A. (1973). An Economic Approach to Legal Procedure and Judicial Administration. Journal of Legal Studies. 2(2): 399 - 458.
} 
argued in literature that criminal law may be used to induce organizational change to prevent $\mathrm{OHS}$ violations in future. ${ }^{60}$ In reality in many legal systems there are now possibilities to use either the criminal law or administrative penal law to particular violations of OHS regulation or in some cases even a combination of those. ${ }^{61}$

\section{OPTIMAL SANCTIONS FOR VIOLATIONS OF OHS REGULATIONS}

Following the discussion of the choice between administrative and criminal law it may be clear that when optimal deterrence can be achieved equally through fines and prison sanctions, administrative fines are preferred. As it was indicated above, that is why the fine has been advanced as the ideal sanction in case of corporate crimes. ${ }^{62}$ This was, however, criticized by Shavell who argued that fines only could work as an effective deterrent if there is no insolvency problem. As we have argued above, in case of a low probability of detection and an insolvency risk non-monetary sanctions will have to be applied. ${ }^{63}$

The result of this economic literature is therefore that the optimal sanction in case of a violation of OHS regulation depends upon a variety of elements, such as the benefit to the employer, the probability of detection, the social harm caused, the insolvency risk and the costs of the sanction to be imposed. Optimal sentencing policy would hence consist of applying fines as long as possible (in the light of the insolvency risk) and to combine them in a differentiated manner with non-monetary sanctions where necessary. ${ }^{64}$ In reality of sentencing practice this can be different. This is more particularly the case in the U.S. where strict sentencing guidelines apply to which the judge in principle should comply. Frank Easterbrook has strongly opposed this idea of strict sentencing guidelines, arguing that 'there is no correct price for crime in the same way that there is no correct price for apples'. He holds that the price of crime depends upon a variety of elements, indicated above, which enable the judge to determine the optimal penalty in a differentiated way. ${ }^{65}$ Easterbrook therefore supports discretionary sanctioning powers of the judge, arguing that this will allow

60 Fisse, B. (1983). Reconstructing Corporate Criminal Law: Deterrence, Retribution, Fault and Sanctions. Southern California Law Review. 56: 1141-1246.

61 Garoupa, N., and Gomez-Pomar, F. (2004). Punish Once of Punish Twice: A Theory of the Use of Criminal Sanctions in Addition to Regulatory Penalties. American Law and Economics Review. 6(2): 410-433.

62 Posner, R.A. (1979). Optimal Sentences for White Collar Criminals. American Criminal Law Review. 17: 400-418.

63 Shavell, S. (1985). Criminal Law and the Optimal Use of Non-Monetary Sanctions. Columbia Law Review. 85: 1232-1262.

64 Cooter, R., and Ulen, T. (2004). Law and Economics: Pearson Addison Wesley.

65 Easterbrook, F. (1983). Criminal Procedure as a Market System. Journal of Legal Studies. 12(2): 289332. 
the judge to differentiate the sanctions in a more precise manner, taking into account relevant criteria.

One particular sanction which increasingly gains popularity in the fight against white-collar crime generally is the forfeiture of illegal gains. From a legal perspective, this forfeiture of illegal gain rests on the notion that 'crime should not pay'. The gains obtained by the crime should be removed from the criminal in order to put him back in the status quo ante. ${ }^{66}$ Recently, Bowles, Faure and Garoupa showed that the forfeiture of illegal gain can be efficient in order to provide additional deterrence in case of a low detection rate and low effective fines. ${ }^{67}$ However, early empirical studies by German criminologists showed that the risk of removal of illegal gain had hardly any effect on potential criminals in their decision whether or not to commit the crime. ${ }^{68} \mathrm{It}$ therefore remains debated to what extent the removal of an illegal gain can provide an additional deterrent effect to prevent employers from violating OHS regulation.

Another sanction that increasingly gains popularity is adverse publicity (so-called naming and shaming), increasingly utilised to deter corporate misconduct.. ${ }^{69}$ An additional difference between the administrative sanction and the criminal law is that often it is held that a conviction in a criminal court, more than any other form of punishment, implies stigma and loss of reputation..$^{70}$ In turn, this is expected to add to deterrence. ${ }^{71}$ Some legal systems pick up the 'naming and shaming' idea by providing the possibility for the criminal court to order the publication of a judgement. Yet, the value of this 'shaming' approach to crime is debated. Whereas proponents argue that shaming may add considerably to deterrence at a low cost, critics hold that it might be unjust since its impact is difficult to estimate and might disproportionately affect the corporation. ${ }^{72}$ There are serious concerns that the deterrent effects of shaming policies

66 For an overview of these legal foundations see Faure, M. (2005). Gewinnabschöpfung und Verfall auf ökonomischen Prüfstand. In: Arnold J, others (eds) (2005) Menschengerechtes Strafrecht. Festschrift für Albin Eser zum 70. Geburtstag, pp. 1311-1330. Beck, München, for a comparative overview Kilchling, M (2002). Die Praxis der Gewinnabschöpfung in Europa, Freiburg im Breisgau. Max Planck Institute for Foreign and International Criminal Law.

Bowles, R., Faure, M., and Garoupa, N. (2000). Economic analysis of the removal of illegal gains. International Review of law and Economics. 20: 537-549.

Smettan, J.R. (1992). Kriminelle Bereicherung in Abhängigkeit von Gewinnen, Risiken, Strafen und Moral. Freiburg im Breisgau: Max-Planck-Institut für Internationales Strafrecht. See Skeel, who even discusses cases of shaming by private parties, Skeel, David A., 2000. Shaming in Corporate Law. University of Pennsylvania Law Review, 149, 1811-1868.

70 Galbiati, R., and Garoupa, N.M. (2005). Keeping Stigma Out of Administrative Law: An Explanation of Consistent Beliefs (June 2005) Available at SSRN: http://ssrn.com/abstract=738403 or DOI: 10.2139/ssrn.738403.

71 Braithwaite, J. (1989). Crime, Shame and Reintegration. Cambridge: Cambridge University Press, Cowan, A. (1991). Scarlet Letters for Corporations? Punishment by Publicity under the New Sentencing Guidelines. California Law Review. 65: 2387-2420.

72 A. Cowan shortly discusses and rejects the proportionality argument, see Cowan, Andrew, 1991. Scarlet Letters for Corporations? Punishment by Publicity under the New Sentencing Guidelines. California Law Review, 65, 2387-2420, p.2408-2411. 
are sporadic, ${ }^{73}$ unreliable, ${ }^{74}$ and highly context dependent. ${ }^{75}$ R. Posner and Rasmusen point to problems of incorrect information and mistaken shame creation which could impose excessive costs upon - possibly innocent - offenders. ${ }^{76}$ That would for example be an argument to allow reputational sanctions only when a court procedure with high evidentiary thresholds intended to reduce such errors has been followed. Allowing administrative authorities to 'shame' offending employers may lead to excessive error costs and should from that perspective be avoided. Whereas the empirical evidence of the deterrent value of shaming is scarce, ${ }^{77}$ many are optimistic and stress that a major advantage of 'shaming' is that it can reach additional deterrence at a relatively low cost. ${ }^{78}$ Yet, more empirical research is needed to establish in how far naming and shaming could be applicable and effective within the context of OHS enforcement.

\section{ROLE OF THIRD PARTIES?}

Above, we already stressed the potentially crucial role of third parties (more particularly employees and trade unions) in OHS enforcement. We discussed in several places that this role may well depend upon the intensity of trade unionism, the nature of the offence involved and the labour relationships in the particular jurisdiction. In case of a violation of OHS regulation, employees who suffer damage may also want to bring a private suit in addition to the public enforcement. In principle, the law and economics literature holds that in as far as victims join the public enforcement with their private suit this leads to additional deterrence at no additional costs. ${ }^{79}$ Moreover, victims who have personally suffered loss have better incentives than officials to enforce regulation upon the negligent employer. To some extent, the rights of employees to

$73 \quad$ See for example de Prez, P. (2000). Beyond Judicial Sanctions: the Negative Impact of Conviction for Environmental Offences. Environmental Law Review. 11: 11-22, p. 20 et seq.

74 Coffee, J.C. (1981). "No Sould to Damn: No Body to Kick": An Unscandalized Inquiry into the Problem of Corporate Punishment. Michigan law Review. 79(3): 386-459, p. 427.

75 Kahan, D.M., and Posner, E.A. (1999). Shaming White-Collar Criminals: A Proposal for Reform of the Federal Sentencing Guidelines. Journal of Law and Economics. 42: 365-391, p. 387.

76 Posner, R.A., and Rasmusen, E.B. (1999). Creating and Enforcing Norms, with Special Reference to Sanctions. International Review of Law and Economics. 19: 369-382, p. 380.

77 Kahan, D.M. (1996). What Do Alternative Sanctions Mean? University of Chicago Law Review. 63: 591-654, Kahan, D.M., and Posner, E.A. (1999). Shaming White-Collar Criminals: A Proposal for Reform of the Federal Sentencing Guidelines. Journal of Law and Economics. 42: 365-391, de Prez, P. (2000). Beyond Judicial Sanctions: the Negative Impact of Conviction for Environmental Offences. Environmental Law Review. 11: 11-22.

78 Kahan, D.M., and Posner, E.A. (1999). Shaming White-Collar Criminals: A Proposal for Reform of the Federal Sentencing Guidelines. Journal of Law and Economics. 42: 365-391, Rasmusen, E. (1996). Stigma and Self-fulfilling Expectations of Criminality. Journal of Law and Economics. 39: 519-543; Buell SW (2006), 'The Blaming Function of Entity Criminal Liability', Indiana Law Journal, 81, pp. 473-537.

79 Burrows, P. (1999). Combining Regulation and Legal Liability for the Control of External Costs. International Review of Law and Economics. 19: 227 - 244. 
enforce regulation as well can provide a counterweight for an enforcement deficit by the health and safety inspectorates. There are several ways in which in this respect the employee can join the public enforcement. One possibility is that in negligence based tort law systems the employee will have an incentive to show that the OHS regulation was violated. If this can be proven, it will be considered a fault in the tort case filed by the employee. ${ }^{80}$ In some legal systems the employee, victim of an industrial accident or occupational disease can join his private claim to the formal (criminal) procedure as 'partie civile'. This shows that even though there are strong arguments in favour of public enforcement of OHS regulation instead of private, this does not exclude that a private claim by the employee can have an additional deterrent effect when joined to the public enforcement procedure. However, one should also recall that there may be many reasons why the employee may not be able to exercise his private rights, lacking information or high costs just being some of those. Moreover, the employee will obviously only have incentives to bring his private claim when the violation of OHS regulations also resulted in damage.

The role of third parties in OHS enforcement is not limited to lawsuits by employees only. One could also consider to give trade unions the right to bring prosecutions for OHS offences. ${ }^{81}$ The only disadvantage of third parties bringing a private suit separately from the public enforcement procedure mentioned in literature is that it may run counter to the agency's decision for example not to prosecute given the relatively minor importance of the infringement. ${ }^{82}$ Here plays the classic problem that the victims' incentives to sue may be different than the social reasons. In some cases employee activism leading to enforcement where the agency decided that it would not be cost-effective to do so may thus lead to inefficiencies. On the other hand, one could equally argue that still granting the employee the right to bring his private suit has exactly the major advantage that this may counter imperfect enforcement by the public authorities resulting e.g. from collusion or capturing problems. Braithwaite, therefore, proposes giving trade unions the right and even encouraging trade unions to bring prosecutions if the labour inspectorate does not do so. However, if the OHS agency does take enforcement action, he proposes that such private action should be restricted. 83

$80 \quad$ Faure MG, Van den Bergh R (1987) Negligence, Strict Liability and Regulation of Safety under Belgian Law: An Introductory Economic Analysis. Geneva Papers on Risk and Insurance 12, 95.

81 Suggested by Gunningham, N., and Johnstone, R. (1999). Regulating Workplace Safety: Systems and Sanctions. Oxford: Oxford University Press, p. 335.

82 Ogus, A., Faure, M., and Philipsen, N. (2006). Best Practices for Consumer Policy: Report on the Effectiveness of Enforcement Regimes. Paris: OECD, Committee on Consumer Policy.

83 Braithwaite, J. (2004). Restorative and Responsive Regulation of OHS. In L. Bluff, N. Gunningham, and R. Johnstone (Eds.), OHS Regulation for a Changing World of Work. 194-208. Sydney: The Federation Press, p. 204. 


\section{CONCLUDING REMARKS}

Using the existing economic models of law enforcement, among them in the fields of consumer protection and environmental legislation, we aimed to identify costeffective techniques to enforce OHS regulation. Note that we did not discuss the quality and the efficiency of OHS regulation as such. Given the existence of particular regulation, we assumed that more compliance is always desirable because it leads to better OHS outcomes and wondered how a cost-effective legal design of enforcement mechanisms could be achieved.

We started by noting that a typical element of OHS regulation is that it is applied in an employee-employer relationship which in principle provides scope for private enforcement by employees or by trade unions. However, we identified many reasons why such private enforcement may not take place such as lack of information but also employee's fears of sanctions by the employer. Moreover, we argued that a distinctive feature of OHS regulation is that it aims at protecting non-financial values such as life and human safety which makes the protected interests more important than when, say, only financial interests were at stake. Private enforcement which is necessarily harmbased, therefore, is not the best option since non-pecuniary loss cannot be undone as easily as financial loss. These are strong reasons in favour of proactive inspection whereby inspectorates monitor compliance with OHS regulation ex ante and do not wait until a violation appears and is reported to the inspectorate. Such a reactive approach may in our view lead to under-deterrence although in legal systems where a strong employee and trade union activism would exist it may be possible to rely more on reactive than proactive monitoring. Still, the danger may exist that also for active employees a violation may be difficult to detect and an intervention may often come too late (i.e. after an accident happens). For the same reason we suggested to grant the inspectorate post-detection discretion allowing him to differentiate between cases. Post-detection discretion then has the advantage that in a cooperative spirit the inspectorate can inform the employer about his duties and therewith increase compliance. Discretionary enforcement, moreover, cures many inefficiencies of the law which often tends to be over-inclusive. ${ }^{84}$ However, such a cooperative strategy may only work with first offenders and in case of minor offences. Moreover, it can only work in a culture where inspectors act in the public interest and not when justified fears exist that a collusive relationship between the employer and the inspectorate may lead to under-enforcement.

Within the context of sanctioning measures, we argued that there are strong reasons for using administrative sanctions (more particularly administrative fines) in cases where the benefit of a violation to the employer is minor, the probability of detection was reasonably high and therefore a modest fine could lead to cost-effective

$84 \quad$ Veljanovski, C.G. (1984). The Economics of Regulatory Enforcement. In K. Hawkins, and J.M. Thomas (Eds.), Enforcing Regulation. 171-186: Kluwer-Nijhoff. 
deterrence. Thus the more costly criminal law system could be reserved for cases where (e.g. because of higher social damage or a lower probability of detection) a high sanction is needed. This is particularly the case when non-monetary sanctions (such as imprisonment) would have to be applied. Given the higher error costs in the administrative procedure a prison sanction should only be imposed after the criminal procedure (with its higher evidentiary thresholds) has been followed. For obvious reasons economists would suggest use of the fine as cost-effective sanction as long as the solvency limit of the employer is not reached. Moreover, some experimenting with complementary sanctions such as e.g. the removal of illegal gain may provide additional deterrence. One traditional important reason to use the criminal law rather than administrative law is that criminal law would have a stigmatising effect which administrative sanctions lack. However, the extent to which this is the case may well depend upon the culture in the particular legal system and upon the type of violation and employer. If one believes reputational sanctions to provide a low-cost additional deterrent, the mandatory publication of a judgement may be warranted. However, given high error costs this should be reserved for the criminal law rather than be used in administrative proceedings as well. Moreover, even though there are strong reasons in favour of public enforcement of OHS regulation, private enforcement by victims may still provide additional deterrence e.g. when the victim can join the public procedure to support public enforcement efforts.

We have hence shown that on the basis of some economic insights suggestions can be formulated for a cost-effective legal design of the enforcement of OHS regulation. Obviously, this analysis could be further refined, e.g. by looking at the possibility to include additional sanctions either of administrative or criminal nature aiming e.g. at reparation of harm done or preventing future losses by prohibiting the employer to use dangerous substances or installations. Also, the analysis could be refined by taking into consideration the fact that most employers are organized as legal entities, which may necessitate relaxing the conditions of corporate criminal liability. Those are issues for further research. The economic criteria we advanced also show that to some extent the cost-effective legal design of the enforcement mechanism will also depend upon elements of the particular legal system such as e.g. the existence of a reliable and independent network of inspectors and the presence of trade unions. Hence, there may well be differences between the legal systems. Moreover, choices e.g. between particular enforcement styles (deterrence versus cooperation) or sanctioning systems (administrative versus criminal), is sometimes also strongly bound to existing legal cultures in a particular system. There may hence by some 'path dependency' which may explain why a particular legal design is chosen even if from an economic perspective this may not necessarily be the optimal one. The challenge is clearly to further refine this analysis by comparing it to the actual enforcement of OHS regulation in particular legal systems. This could provide insights on whether differences in legal design also provide better results as far as compliance with OHS regulation is concerned. 
Finally, we should stress that our analysis of course was limited to an examination of public enforcement mechanisms to enforce OHS regulations. However, there are, in addition to the incentives provided through enforcement, other quite powerful reasons for firms to comply with OHS regulation. For example, those are incentives provided for by the insurance systems, concerns about one's self safety, morality or firm's value. ${ }^{85}$ The final answer on how to guarantee safety at the workplace may therefore need a more integrated approach whereby the various effects of market incentives, liability rules, the role of insurance companies, enforcement efforts and trade unionism are considered altogether with respect to their ability to provide a safe and healthy workplace.

$85 \quad$ Fry CL, Lee I (1989), 'OSHA Sanctions and the Value of the Firm', Financial Review, 24, pp. 599610. 